OPEN ACCESS

Edited by:

Lars Rogge,

Institut Pasteur, France

Reviewed by:

Tony Kenna

Queensland University of

Technology, Australia

Henri-Jean Garchon,

Université de Versailles

Saint-Quentin-en-Yvelines, France

*Correspondence:

Chen Liye

liye.chen@ndorms.ox.ac.uk

${ }^{\dagger}$ These authors have contributed equally to this work

Specialty section:

This article was submitted to Cytokines and Soluble Mediators in

Immunity,

a section of the journal

Frontiers in Immunology

Received: 31 October 2020

Accepted: 22 January 2021

Published: 17 February 2021

Citation:

Nancy Z, Yan L, Hui S, Paul B and Liye C (2021) From the Genetics of Ankylosing Spondylitis to New Biology

and Drug Target Discovery.

Front. Immunol. 12:624632.

doi: 10.3389/fimmu.2021.624632

\section{From the Genetics of Ankylosing Spondylitis to New Biology and Drug Target Discovery}

\author{
Zaarour Nancy ${ }^{1 \dagger}$, Li Yan ${ }^{2 \dagger}$, Shi Hui ${ }^{1}$, Bowness Paul ${ }^{1}$ and Chen Liye ${ }^{1 *}$ \\ ${ }^{1}$ Nuffield Department of Orthopaedics, Rheumatology and Musculoskeletal Sciences, University of Oxford, Oxford, \\ United Kingdom, ${ }^{2}$ Department of Rheumatology, The First Affiliated Hospital of Xiamen University, Medical College of Xiamen \\ University, Xiamen, China
}

Genome-wide association studies (GWAS) have identified 113 single nucleotide polymorphisms (SNPs) affecting the risk of developing ankylosing spondylitis (AS), and an on-going GWAS study will likely identify 100+ new risk loci. The translation of genetic findings to novel disease biology and treatments has been difficult due to the following challenges: (1) difficulties in determining the causal genes regulated by disease-associated SNPs, (2) difficulties in determining the relevant cell-type(s) that causal genes exhibit their function(s), (3) difficulties in determining appropriate cellular contexts to interrogate the functional role of causal genes in disease biology. This review will discuss recent progress and unanswered questions with a focus on these challenges. Additionally, we will review the investigation of biology and the development of drugs related to the IL-23/IL-17 pathway, which has been partially driven by the AS genetics, and discuss what can be learned from these studies for the future functional and translational study of AS-associated genes.

Keywords: ankylosing spondylitis, GWAS, functional genomics, IL-23/IL-17 axis, drug target, IL-1beta, genetics

\section{INTRODUCTION}

Ankylosing Spondylitis (AS) is a common form of immune-mediated arthritis that predominantly affects the sacroiliac and spinal joints and can result in excessive ossification of the affected tissues. Over the past decade the successful introduction of new treatments for AS (therapeutic monoclonal antibodies targeting tumor necrosis factor (TNF)- $\alpha$ and interleukin (IL)-17A) has highlighted some of the important pathological pathways involved. However, $<50 \%$ of patients achieve good response (ASAS40) to either TNF- $\alpha$ or IL-17A blockade $(1,2)$. More importantly, there is no cure for AS and most patients require lifelong medication (with consequent potential adverse effects) to control their symptoms. Therefore, identifying novel therapeutic targets could have important benefits for patients with AS.

The value of genetics in drug discovery is increasingly appreciated $(3,4)$. The induction of IL-17A blockade in AS was partially driven by genetic studies showing multiple disease associations with genes involved in IL-23/IL-17A pathways (e.g., IL6R, IL23R, TYK2, IL1R1/2, IL27, STAT3) (5). Genome-wide association studies (GWAS) have already identified 113 single nucleotide polymorphisms (SNPs) affecting the risk of developing AS $(6,7)$. To date, there is a plausible explanation for only a minority of these genetic associations, substantially impeding their translation into therapeutic options. 
The functional investigation of genetics association currently encountered a number of challenges: (1) difficulties in determining the causal genes regulated by disease-associated SNPs, (2) difficulties in determining the relevant cell-type(s) that causal genes exhibit their function(s), (3) difficulties in determining appropriate cellular contexts to interrogate the functional role of causal genes in disease biology. This review will discuss recent progress and remaining challenges. While appreciating the importance of identifying causal SNPs, limited by the length of this mini-review, we choose to refer readers to recent review rather than discuss this topic here (8). Following the identification of causal genes and related cellular contexts, immunological research is vital for drug discovery. We will use the IL-23/IL-17 pathway as an exemplar, in part driven by the AS genetics, and discuss what can be learned from these studies for the future functional and translational study of AS-associated genes.

\section{AS GENETICS}

Genetic contribution to the development of AS was first known following the discovery of HLA-B ${ }^{*} 27$ as a strong genetic risk factor in 1973 (9-11). In fact, the association was so strong that HLA-B*27 was, for a long time, considered to be the sole genetic factor predisposing individuals to AS. Till 2007, powered by the technical development in SNP genotyping and statistical analysis for GWAS, the first AS GWAS was competed (12). Although with a relatively small sample size (1,000 patients and 1,500 controls), this study identified two key non-MHC genetic risks: IL23R and ERAP1. These findings were subsequently confirmed in a study with a larger cohort, which reported two additional associations with chromosome 2p15 and 21q22 (13). In the same year, a study focusing on 53 known genetic risks in Crohn's disease, a condition clinically related to AS, identified two additional AS-associated loci: 1q32 and STAT3 (14). In 2011, the striking epistasis between ERAP1 and HLA$B^{*} 27$ was found, along with seven additional genetic loci with strong associations with AS (15). The most recent findings were reported from the Immunochip project with the strategy of highdensity genotyping of immune-related loci, which, in part using "multi disease" methodology, has increased the number of SNPs independently affecting the risk of developing AS to $113(6,7)$.

Overall, a significant body of knowledge of AS genetics has been generated over the last decade. This rich and highquality source of genetic risk associations in AS will, after appropriate decoding, provide critical sights in AS biology and new drug targets.

\section{TRANSLATING GENETICS TO NEW BIOLOGY AND DRUG TARGET DISCOVERY}

\section{Recent Technical Advances and Opportunities}

In attempting to reveal the functional basis of genetic risks associated with human diseases, various techniques have been developed over the past few years. We believe that expression quantitative trait loci (eQTL), promoter capture Hi-C (PCHi-C), and HiChIP constitute key advances for the prediction of causal genes through the annotation of genetic risks (Figure 1).

Expression quantitative trait loci (eQTL) identifies genomic variants that contribute to altered expression levels of mRNAs. eQTL have been carried out using various primary human immune cells (monocyte, macrophage, dendritic cell, CD4, CD8, Treg, Th1, Th2, Th17, Tfh, B-cell, NK and neutrophil) in different cellular contexts (resting and activation) (16-21). These data constitute a rich eQTL data resource which can be integrated with summary data from AS GWAS studies for the prediction of the causal genes $(22,23)$. Of note, eQTLs are only present in a proportion of GWAS SNPs $(24,25)$, highlighting the need for additional approaches to link SNP to gene.

The development of chromosome conformation capture (3C) and its related techniques, such as $\mathrm{Hi}-\mathrm{C}$, has allowed the detection of long-range regulatory DNA interactions $(26,27)$. To overcome the nature of complexity and high-cost of $\mathrm{Hi}-\mathrm{C}$, promoter capture Hi-C (PCHi-C) has been developed, combining $\mathrm{Hi}-\mathrm{C}$ with hybridization-based capture of targeted genomic regions (28). PCHi-C has been carried out for various diseases using relevant tissues/organs and/or cells (29-31), but not yet in AS. One dataset, which we believe will be of particular value for AS research, provides high-resolution maps of promoter interactions at the genome-wide level in 17 human primary blood immune cell types (32). HiChIP is another technique derived from $\mathrm{Hi}$ $\mathrm{C}$ which incorporates ChIP-seq-allowing the enrichment of chromatin looping events based on histone modifications (33). H3K27ac HiChIP has been applied to naïve CD4, Th17, and Treg cells to reveal $\mathrm{T}$ cell subtype-specific enhancer-promoter interactions (34). These enhancers often contact genes beyond their nearest neighbor gene-highlighting the importance of SNP annotation using functional genomic datasets. Thus, we believe that the integration of chromatin looping datasets and AS GWAS findings provides a potent approach to predict the causal genes.

Determination of disease-relevant cell-types for functional investigation is a key challenge impeding the translation of genetic findings to new biology and therapeutic options. Some causal genes identified by eQTL or chromatin looping datasets will be limited in their action to specific cell-type(s), guiding the selection of cells to be investigated (Figure 1). However, this information is not always available. In such a scenario interrogation of chromatin accessibility (DNase hypersensitivity assay or ATAC-seq), DNA methylation and histone modifications will be of great use following mapping with GWAS SNPs (Figure 1). The latter include enhancer (e.g., $\mathrm{H} 3 \mathrm{~K} 4 \mathrm{me} 1)$, promoter (H3K4me3), and active enhancer and promoter marks (H3K27ac).

Precise functional testing of predicted causal genes requires knowledge of cellular context(s). This is particularly important for genes where existing knowledge of function is limited, a common situation for GWAS hits. To this end, transcriptional data from patient-derived cells and/or particular disease-related cell-types, such as Th17 cells in AS, would be of great use. For example, if a causal gene is elevated in Th17 cells, one would predict it to be a possible Th17 regulator and test its function in a Th17 functional cellular assay. Single cell RNA 


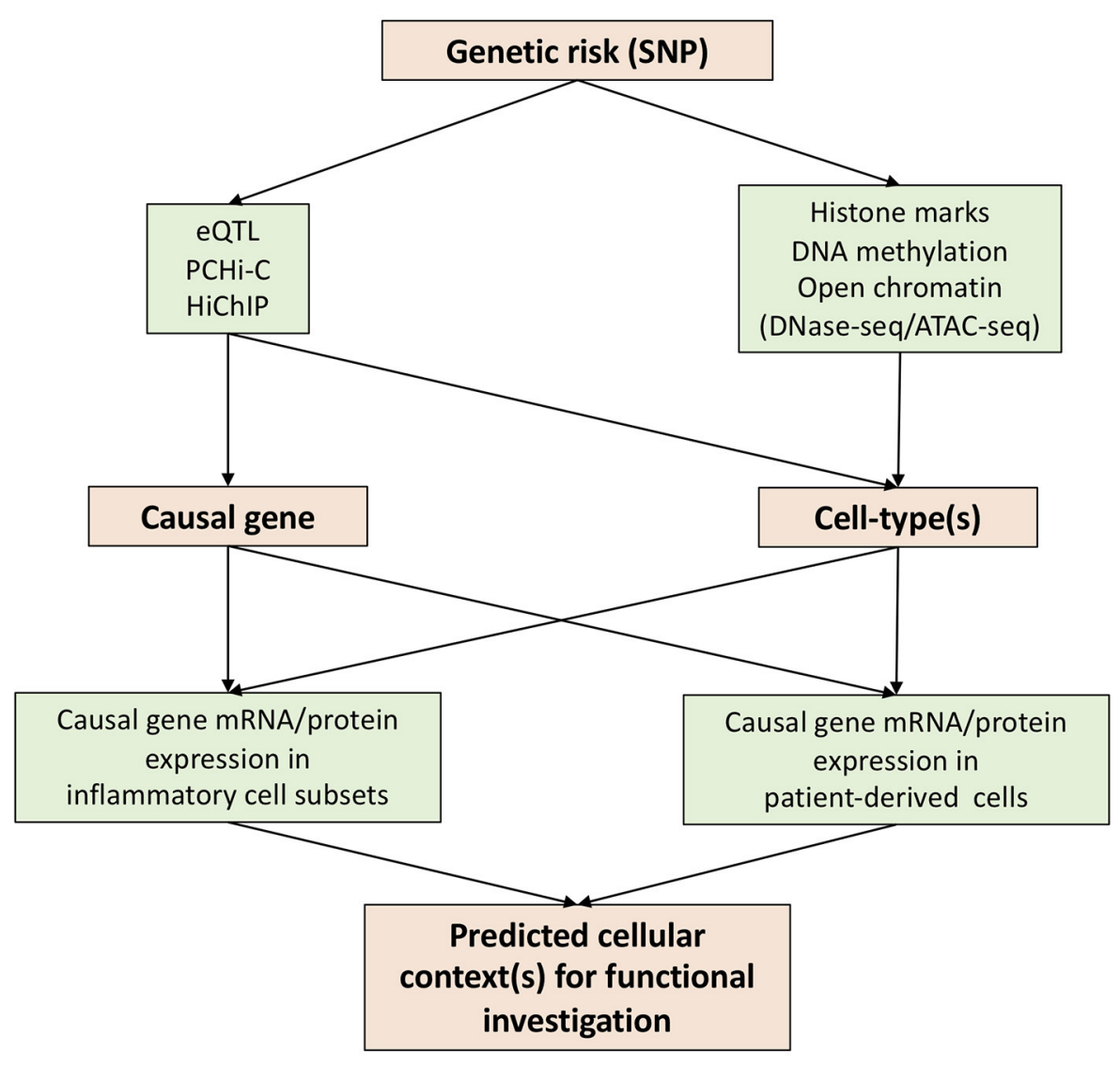

FIGURE 1 | Strategies to translate genetic risk to novel biology.

sequencing (scRNA-seq) would excel here in the provision of gene abundancy data for multiple cell subsets in patient blood or synovium. However, a well-known drawback of scRNA-seq is its inability to detect genes in low abundance. Antibody (CITE-seq) or oligo (BD Rhapsody)-based tagging of genes of interest might go some way to solve this problem. In addition, for genes with available antibodies, mass cytometry or CyTOF is an alternative approach to acquire the expression profile of a gene at the protein level.

\section{Remaining Challenges and Possible Solutions}

eQTLs are frequently different in different cell types. For example, the eQTL link of GAB2 gene with rs2511162 is found for naïve B cells and T cells, but not monocytes (19). Even within one cell-type, eQTLs can be highly context-specific. For example the AA genotype at rs1179625 is associated with higher basal mRNA HIP1 levels in naïve monocytes, but reduced HIP1 upregulation in lipopolysaccharides (LPS)stimulated monocytes (16). Of note, the difference in context is not limited to resting vs. stimulation but may be highly time dependent for a cell-type treated with the same stimuli. For examples, the eQTL linking rs2275888 with IFNB1 gene transcription is present in monocytes after $2 \mathrm{~h}$ LPS-stimulation but not in resting monocytes or those cultured with LPS for $16 \mathrm{~h}$ (16). As mentioned in the previous section, cell-type and context specificity are also present in chromatin looping datasets (PCHi-C and HiChIP). Thus, although current eQTL and chromatin looping datasets have included various conditions for an individual cell-type, they cannot possibly cover all the complex and dynamic microenvironments present in human diseases including AS. Given the high probability of the presence of AS-specific genetic regulations, this knowledge will be crucial in advancing our understanding of the impact of genetic risks on AS biology and unraveling novel mechanisms and therapeutic options. To this end, we propose that functional genomics datasets should ideally be generated using cells from blood or even joint of patients with AS for the provision of diseasespecific insights.

Evidence suggesting key roles for rare immune cell populations in AS has recently emerged,. For example invariant NK cells (iNKT) and $\gamma \delta \mathrm{T}$ cells have recently been reported to be a major source of IL-17 in the inflamed joint (35). These innate-like $\mathrm{T}$ cells are phenotypically and functionally different from conventional $\mathrm{T}$ cells, thus would likely have distinct gene expression mechanisms. Neither eQTL nor chromatin looping datasets have been generated for these un-conventional cell 
types, and we propose that coordinated efforts to generate functional genomic datasets for these cells should be made by the scientific community.

Even within one cell-type, specific subsets might be highly relevant to the pathogenesis of human diseases. For example, using single cell RNA sequencing (scRNA-seq), MerTK+ synovial tissue macrophages have recently been shown to be key for the remission of rheumatoid arthritis after treatment cessation (36). Thus, scRNA-seq-based eQTL studies carried out using patient blood and/or tissue derived cells will be of great value. This approach was first reported in 2018 for a small cohort of 45 healthy donors (37). More recently, the singlecell eQTLGen consortium has been established and will provide standardized pipelines and guidelines for single-cell population genetics studies (38).

Most functional genomics data are at the DNA or RNA level. This does not invariably relate to cellular and cell surface protein expression. Advances in quantitative MS might allow QTL at the protein level. Indeed, quantitative proteomics has been utilized to advance knowledge in biology, such as the dynamic protein landscape of human Th17 differentiation (39), and the underlying mechanism of Myc controlling T cell proteomes and metabolic pathways (40).

It will also be important to contextualize the anatomical location of immune cells and their detailed functional interactions. The human tissue atlas will provide a framework and detailed spatial transcriptomic and protein expression studies of diseased tissue including entheses will undoubtedly enrich current knowledge. Without doubt the greatest knowledge gains will flow from the study of cells from inflamed tissues. We believe that obtaining these from human diseased tissues will be more informative given the limitations of current animal models and the rapid advances in single cell technology.

Moving from tissue level understanding to whole organism will be a further challenge. Animal models of AS have proved useful for studying specific pathogenic processes and offer opportunities for intervention. The HLA-B27 transgenic rat and the SKG mouse have both provided key insights, with the former model confirming the role of HLA B27, myeloid cells and gut flora in disease and the latter confirming the key role for the IL-23-17 pathway (see below). Considering both animal models and human studies it will also be important to distinguish the relative roles of tissue-resident and tissue-specific cells from those of circulating cells. We believe that using animal models to label leucocytes present in the gut mucosa (e.g., with photobleaching or fate mapping) and then follow their potential movement to joints and other inflammatory sites is likely to offer major insights into disease pathogenesis. Ultimately human experimental medicine studies will prove the key arbiters of target selection and will provide a rich source of data.

\section{THE IL-23/IL-17 PATHWAY AND AS}

\section{IL-23/IL-17 Pathway}

IL-23 is formed by P19 and P40 subunits with the later, along with P35, also forming IL-12 (41). IL-23 signals through the IL-23 receptor composed of IL-23R and IL-12R $\beta 1$. IL-12 drives the differentiation of Th1 cells, whereas IL-23 is crucial for the survival and expansion of Th17 cells and can induce IL17 production in memory $\mathrm{T}$ cells $(42,43)$. Additionally, IL23 also induces IL-17 production by $\gamma \delta \mathrm{T}$, NKT and innate lymphoid cells (44-46). In line with this, murine models support the T cell-mediated pathogenic role of IL-23 in inflammation in multiple organs, including joints, gut, brain (47-49). Of note, both IL-23 and IL-17A are required for the development of Spondyloarthritis-like pathology in SKG mice, a T-cell driven AS model with inflammation in arthritis, enthesitis, and ileitis (50).

\section{Relevance to AS Genetics}

More than $90 \%$ of genetic risk SNPs are present in non-coding regions. Thus, IL23R, where genetic risk loci reside both within coding (the cytoplasmic tail) and non-coding regulatory regions, represents the exception rather than the norm. The genetic association of IL23R loci with AS was first reported in 2007 (12), the first elucidated being a coding change SNP, rs11209026, associated with Arg or Gln at position 381 of IL-23R protein. Interestingly, the same SNP also affects the risk of developing inflammatory bowel disease (IBD) (51), a condition closely linked to AS. Indeed, a subgroup of patients with AS develops IBD and the sub-clinical gut inflammation has been reported in over $60 \%$ of patients with AS (52). The same SNP is also associated with psoriasis, another condition closely linked to AS. The protective variant R381Q is associated with reduced function of IL-23R and Th17 response in both CD4 and CD8 cells (53).

\section{Pre-clinical/Clinical Development of Inhibitors Targeting IL-23/IL-17 Pathway}

Antibodies blocking cytokines or receptors related to this pathway have been extensively tested in AS. IL-17A blockers have demonstrated efficacy and been approved for the treatment of AS (54, 55). In contrast, IL-23 inhibitors either targeting P40 or P19, have failed to show efficacy in clinical trials $(56,57)$. These results were unexpected considering the efficacy of IL23 blockers for Crohn's disease, Psoriasis and psoriatic arthritis, conditions related to AS and with IL23R as a genetic risk (5861). Of note, IL-17 inhibition was ineffective in Crohn's disease (62), suggesting the IL-23 biology beyond the simple induction of IL-17 cytokine secretion.

The success of IL-17A blocking and failure of IL-23 inhibition in AS suggested that IL-23 might not be the main driver of IL-17A production in AS. In human, IL-1 $\beta$ and IL- 6 are required for the differentiation of Th17 cells (63). Of interest, IL-1 $\beta$ was essential in pathogen-induced Th17 differentiation to prime IL-17+IFN$\gamma+$ "pathogenic" Th17 cells (64). Additionally, along with IL23 , IL- $1 \beta$ induces IL-17A production by $\gamma \delta \mathrm{T}$ and iNKT cells $(45,65)$, the major source of IL-17A in synovial fluid of patient with AS (35). The recruitment of IL- $1 \beta$-producing myeloid cells has been shown to be a key factor driving the IL-17 secretion by $\gamma \delta \mathrm{T}$ and CD4 cells in the central nervous system (66). Two pieces of evidence link IL-1 $\beta$ to AS pathology: (1) both IL1R1 and IL1R2 are predicted genetic risks in AS (13), (2) monocytes in blood from patients with AS spontaneously produce IL-1 $\beta$ (67). Thus, we propose a model explaining the possible IL-1 $\beta$-driven IL-17 biology in AS (Figure 2). Monocytes stimulated by bacteria 


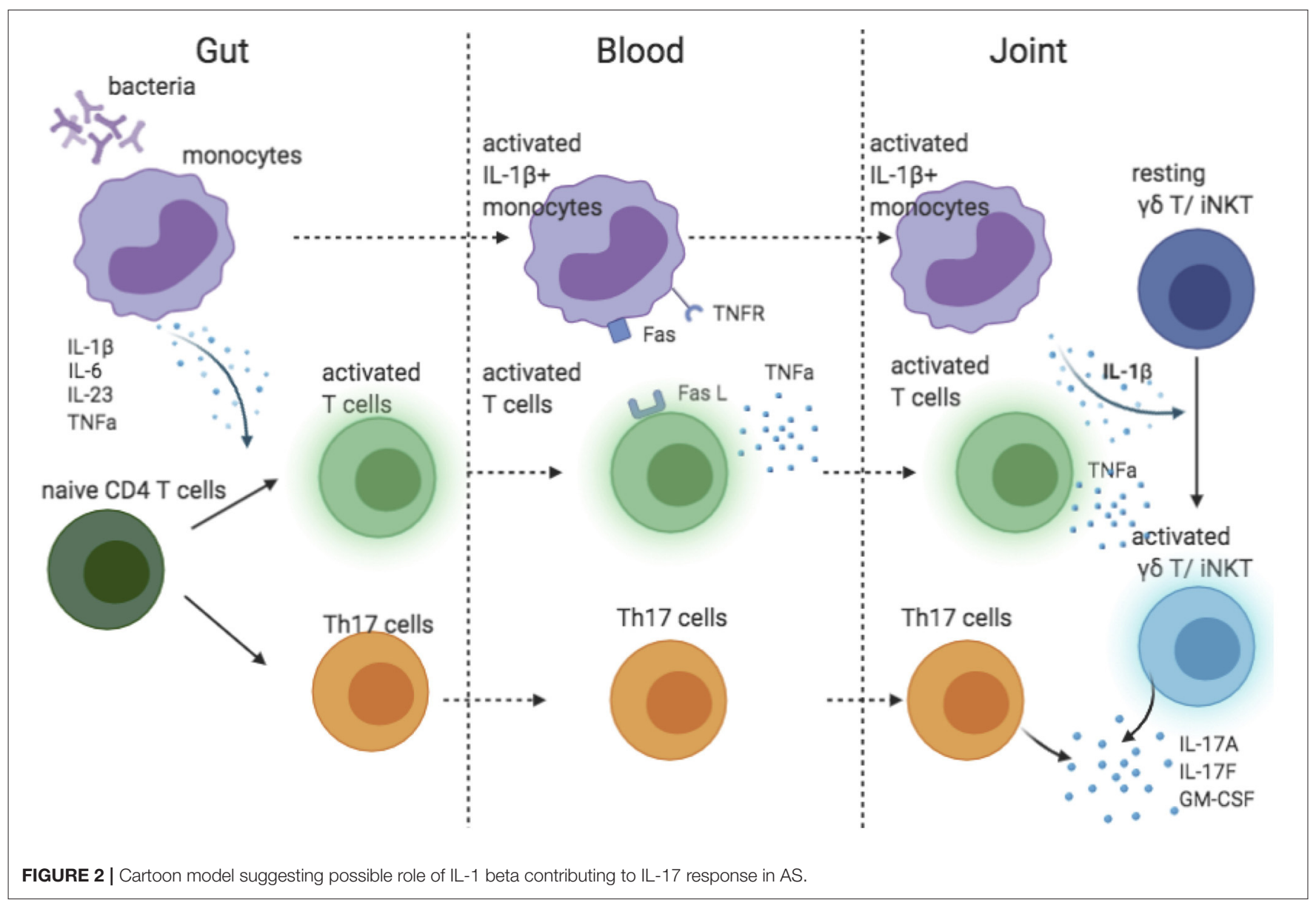

in the gut produce pro-inflammatory cytokines that prime Th17 cells. Attracted by chemokines, IL- $1 \beta$-secreting monocytes travel to the joint(s), where they activate $\gamma \delta \mathrm{T}$ and iNKT cells. Additionally, through a TNFR-Fas-caspase-8-dependent pathway, activated $\mathrm{T}$ cells also induce monocyte IL- $1 \beta$ secretion (68). However, IL-1 $\beta$ is unlikely to be the sole driver of IL-17 in AS because IL-1 $\beta$ inhibition was only effective for a subgroup of patients (69-71).

\section{Lessons From IL-23/IL17}

The therapeutic development of inhibitors targeting the IL-23/IL17 pathway in AS highlights the notion that genetic risk alone is not necessarily the ideal guide to drug target identification and that downstream protein(s) might be better therapeutic options in some cases. Indeed the association of genetic risk with drug success in trails is substantially enhanced when proteins interacting with these risk-associated gene products are included (72). Considering the diseases that share IL23R risk associations, significant differences in therapeutic response to different agents have already emerged. The reasons why IL-23 neutralization proved highly beneficial in psoriasis but without efficacy (at least in initial trials) in Ankylosing Spondylitis, whereas IL-17 neutralization proved therapeutic in Psoriasis, psoriatic arthritis and ankylosing Spondylitis but not Crohn's disease have been discussed by Siebert and colleagues (73). Thus, it is increasingly clear that, following the identification of the causal genes, detailed understanding of the biological functions of the associated proteins in the context of both tissue site and stage of disease is crucial.

\section{DISCUSSION}

Exciting progress has been made in the genetics of AS, resulting in identification of over one hundred genetic variants that affect the risk of disease development. Entering the postGWAS era, we have encountered multiple challenges and bottlenecks in the translation of GWAS findings to new biology and drug targets. With the rapid development of functional genomic techniques/methods and transcriptomic and phenotypic profiling of primary cells at single cell resolution, it is now possible to predict both causal genes and their relevant cell-type. This will allow us to more rigorously investigate the cellular contexts of disease pathogenesis and to functionally validate therapeutic targets. However, disease-specific functional genomic datasets and those for rarer immune cells are currently not available, representing opportunities for future research. The successful development of drugs targeting the IL-23/IL-17 axis for conditions genetically 
associated with IL23R is a great example demonstrating the value of genetics in drug development. We also learned that causal genes are not always the best drug targets, highlighting the importance of establishing downstream pathways. Thus, an in-depth understanding of causal generelated biology is absolutely crucial for the development of novel treatment options.

\section{AUTHOR CONTRIBUTIONS}

All authors listed have made a substantial, direct and intellectual contribution to the work, and approved it for publication.

\section{REFERENCES}

1. Braun J, Kiltz U, Heldmann F, Baraliakos X. Emerging drugs for the treatment of axial and peripheral spondyloarthritis. Expert Opin Emerg Drugs. (2015) 20:1-14. doi: 10.1517/14728214.2015.993378

2. Marzo-Ortega H, Sieper J, Kivitz A, Blanco R, Cohen M, Martin R, et al. Secukinumab and sustained improvement in signs and symptoms of patients with active ankylosing spondylitis through two years: results from a phase III study. Arthritis Care Res (Hoboken). (2017) 69:102029. doi: 10.1002/acr.23233

3. King EA, Davis JW, Degner JF. Are drug targets with genetic support twice as likely to be approved? Revised estimates of the impact of genetic support for drug mechanisms on the probability of drug approval. PLoS Genet. (2019) 15:e1008489. doi: 10.1371/journal.pgen.1008489

4. Nelson MR, Tipney H, Painter JL, Shen J, Nicoletti P, Shen Y, et al. The support of human genetic evidence for approved drug indications. Nat Genet. (2015) 47:856-60. doi: 10.1038/ng.3314

5. Bianchi E, Rogge L. The IL-23/IL-17 pathway in human chronic inflammatory diseases - new insight from genetics and targeted therapies. Microbes Infect. (2019) 21:246-53. doi: 10.1016/j.micinf.2019.06.009

6. International Genetics of Ankylosing Spondylitis C, Cortes A, Hadler J, Pointon JP, Robinson PC, Karaderi T, et al. Identification of multiple risk variants for ankylosing spondylitis through high-density genotyping of immune-related loci. Nat Genet. (2013) 45:730-8. doi: 10.1038/ng.2667

7. Ellinghaus D, Jostins L, Spain SL, Cortes A, Bethune J, Han B, et al. Analysis of five chronic inflammatory diseases identifies 27 new associations and highlights disease-specific patterns at shared loci. Nat Genet. (2016) 48:510-8. doi: $10.1038 /$ ng. 3528

8. Schaid DJ, Chen W, Larson NB, From genome-wide associations to candidate causal variants by statistical fine-mapping. Nat Rev Genet. (2018) 19:491504. doi: 10.1038/s41576-018-0016-z

9. Caffrey MF, James DC, Human lymphocyte antigen association in ankylosing spondylitis. Nature. (1973) 242:121. doi: 10.1038/242121a0

10. Brewerton DA, Hart FD, Nicholls A, Caffrey M, James DC, Sturrock RD. Ankylosing spondylitis and HL-A 27. Lancet. (1973) 1:904-7. doi: 10.1016/S0140-6736(73)91360-3

11. Schlosstein L, Terasaki PI, Bluestone R, Pearson CM. High association of an HL-A antigen, W27, with ankylosing spondylitis. N Engl J Med. (1973) 288:704-6. doi: 10.1056/NEJM197304052881403

12. Wellcome Trust Case Control C, C. Australo-Anglo-American Spondylitis, Burton PR, Clayton DG, Cardon LR, Craddock N, et al. Association scan of 14,500 nonsynonymous SNPs in four diseases identifies autoimmunity variants. Nat Genet. (2007) 39:1329-37. doi: 10.1038/ng.2007.17

13. Australo-Anglo-American Spondyloarthritis C, Reveille JD, Sims AM, Danoy P, Evans DM, Leo P, et al. Genome-wide association study of ankylosing spondylitis identifies non-MHC susceptibility loci. Nat Genet. (2010) 42:1237. doi: $10.1038 /$ ng.513

14. Danoy P, Pryce K, Hadler J, Bradbury LA, Farrar C, Pointon J, et al. Association of variants at $1 \mathrm{q} 32$ and STAT3 with ankylosing spondylitis suggests genetic overlap with Crohn's disease. PLoS Genet. (2010) 6:e1001195. doi: 10.1371/journal.pgen.1001195

\section{FUNDING}

This work was funded by Versus Arthritis (CL), Innovative Medicines Initiative (IMI) ( $\mathrm{ZN}$ and $\mathrm{BP}$ ), by the National Institute for Health Research (NIHR) Oxford Biomedical Research Centre (BP). BP and $\mathrm{SH}$ received research support from GlaxoSmithKline (GSK). The views expressed are those of the author(s) and not necessarily those of the National Health Service, the NIHR or the Department of Health. GlaxoSmithKline (GSK) was not involved in the study design, collection, analysis, interpretation of data, the writing of this article or the decision to submit it for publication.

15. Evans DM, Spencer CC, Pointon JJ, Su Z, Harvey D, Kochan G, et al. Interaction between ERAP1 and HLA-B27 in ankylosing spondylitis implicates peptide handling in the mechanism for HLA-B27 in disease susceptibility. Nat Genet. (2011) 43:761-7. doi: 10.1038/ng0911$919 \mathrm{a}$

16. Fairfax BP, Humburg P, Makino S, Naranbhai V, Wong D, Lau E, et al. Innate immune activity conditions the effect of regulatory variants upon monocyte gene expression. Science. (2014) 343:1246949. doi: 10.1126/science. 1246949

17. Lee MN, Ye C, Villani AC, Raj T, Li W, Eisenhaure TM, et al. Common genetic variants modulate pathogen-sensing responses in human dendritic cells. Science. (2014) 343:1246980. doi: 10.1126/science.1246980

18. Alasoo K, Rodrigues J, Mukhopadhyay S, Knights AJ, Mann AL, Kundu K, et al. Shared genetic effects on chromatin and gene expression indicate a role for enhancer priming in immune response. Nat Genet. (2018) 50:42431. doi: 10.1038/s41588-018-0046-7

19. Schmiedel BJ, Singh D, Madrigal A, Valdovino-Gonzalez AG, White BM, Zapardiel-Gonzalo J, et al. Impact of Genetic Polymorphisms on Human Immune Cell Gene Expression. Cell. (2018) 175:1701-15 e16. doi: 10.1016/j.cell.2018.10.022

20. Momozawa Y, Dmitrieva J, Theatre E, Deffontaine V, Rahmouni S, Charloteaux B, et al. IBD risk loci are enriched in multigenic regulatory modules encompassing putative causative genes. Nat Commun. (2018) 9:2427. doi: 10.1038/s41467-018-04365-8

21. Naranbhai V, Fairfax BP, Makino S, Humburg P, Wong D, Ng E, et al. Genomic modulators of gene expression in human neutrophils. Nat Commun. (2015) 6:7545. doi: 10.1038/ncomms8545

22. Zhu Z, Zhang F, Hu H, Bakshi A, Robinson MR, Powell JE, et al. Integration of summary data from GWAS and eQTL studies predicts complex trait gene targets. Nat Genet. (2016) 48:481-7. doi: 10.1038/ng.3538

23. Giambartolomei C, Vukcevic D, Schadt EE, Franke L, Hingorani AD, Wallace C, et al. Bayesian test for colocalisation between pairs of genetic association studies using summary statistics. PLoS Genet. (2014) 10:e1004383. doi: 10.1371/journal.pgen.1004383

24. Huang H, Fang M, Jostins L, Umicevic Mirkov M, Boucher G, Anderson $\mathrm{CA}$, et al. Fine-mapping inflammatory bowel disease loci to single-variant resolution. Nature. (2017) 547:173-8. doi: 10.1038/nature22969

25. Vandiedonck C, Genetic association of molecular traits: a help to identify causative variants in complex diseases. Clin Genet. (2018). 93:52032. doi: $10.1111 /$ cge. 13187

26. Dekker J, Rippe K, Dekker M, Kleckner N. Capturing chromosome conformation. Science. (2002) 295:1306-11. doi: 10.1126/science.1067799

27. Lieberman-Aiden E, van Berkum NL, Williams L, Imakaev M, Ragoczy $\mathrm{T}$, Telling $\mathrm{A}$, et al. Comprehensive mapping of long-range interactions reveals folding principles of the human genome. Science. (2009) 326:28993. doi: 10.1126/science. 1181369

28. Mifsud B, Tavares-Cadete F, Young AN, Sugar R, Schoenfelder S, Ferreira $\mathrm{L}$, et al. Mapping long-range promoter contacts in human cells with highresolution capture Hi-Nat Genet C. (2015). 47:598-606. doi: 10.1038/ng.3286

29. Miguel-Escalada I, Bonas-Guarch S, Cebola I, Ponsa-Cobas J, MendietaEsteban J, Atla G, et al. Human pancreatic islet three-dimensional chromatin 
architecture provides insights into the genetics of type 2 diabetes. Nat Genet. (2019) 51:1137-48. doi: 10.1038/s41588-019-0457-0

30. Martin P, McGovern A, Orozco G, Duffus K, Yarwood A, Schoenfelder $\mathrm{S}$, et al. Capture Hi-C reveals novel candidate genes and complex longrange interactions with related autoimmune risk loci. Nat Commun. (2015) 6:10069. doi: $10.1038 /$ ncomms 10069

31. Montefiori LE, Sobreira DR, Sakabe NJ, Aneas I, Joslin AC, Hansen GT, et al. A promoter interaction map for cardiovascular disease genetics. Elife. (2018) 7:e35788. doi: 10.7554/eLife.35788

32. Javierre BM, Burren OS, Wilder SP, Kreuzhuber R, Hill SM, Sewitz $\mathrm{S}$, et al. Lineage-specific genome architecture links enhancers and noncoding disease variants to target gene promoters. Cell. (2016) 167:1369-84 e19. doi: 10.1016/j.cell.2016.09.037

33. Mumbach MR, Rubin AJ, Flynn RA, Dai C, Khavari PA, Greenleaf WJ, et al. HiChIP: efficient and sensitive analysis of protein-directed genome architecture. Nat Methods. (2016) 13:919-22. doi: 10.1038/nmeth.3999

34. Mumbach MR, Satpathy AT, Boyle EA, Dai C, Gowen BG, Cho SW, et al. Enhancer connectome in primary human cells identifies target genes of disease-associated DNA elements. Nat Genet. (2017) 49:160212. doi: $10.1038 /$ ng. 3963

35. Venken K, Jacques P, Mortier C, Labadia ME, Decruy T, Coudenys J, et al. RORgammat inhibition selectively targets IL-17 producing iNKT and gammadelta-T cells enriched in Spondyloarthritis patients. Nat Commun. (2019) 10:9. doi: 10.1038/s41467-018-07911-6

36. Alivernini S, MacDonald L, Elmesmari A, Finlay S, Tolusso B, Gigante MR, et al. Distinct synovial tissue macrophage subsets regulate inflammation and remission in rheumatoid arthritis. Nat Med. (2020) 26:1295-306. doi: 10.1038/s41591-020-0939-8

37. van der Wijst MGP, Brugge H, de Vries DH, Deelen P, Swertz MA, S. LifeLines Cohort, et al. Single-cell RNA sequencing identifies celltypespecific cis-eQTLs and co-expression QTLs. Nat Genet. (2018) 50:49397. doi: 10.1038/s41588-018-0089-9

38. van der Wijst $\mathrm{M}$, de Vries DH, Groot HE, Trynka G, Hon CC, Bonder MJ, et al. The single-cell eQTLGen consortium. Elife. (2020) 9:e52155. doi: 10.7554/eLife.52155

39. Tripathi SK, Valikangas T, Shetty A, Khan MM, Moulder R, Bhosale $\mathrm{SD}$, et al. Quantitative proteomics reveals the dynamic protein landscape during initiation of human Th17 cell polarization. iScience. (2019) 11:334355. doi: 10.1016/j.isci.2018.12.020

40. Marchingo JM, Sinclair LV, Howden AJ, Cantrell DA. Quantitative analysis of how Myc controls T cell proteomes and metabolic pathways during T cell activation. Elife. (2020) 9:e53725. doi: 10.7554/eLife.53725

41. Oppmann B, Lesley R, Blom B, Timans JC, Xu Y, Hunte B, et al. Novel p19 protein engages IL-12p40 to form a cytokine, IL-23, with biological activities similar as well as distinct from IL-12. Immunity. (2000) 13:71525. doi: 10.1016/S1074-7613(00)00070-4

42. Aggarwal S, Ghilardi N, Xie MH, de Sauvage FJ, Gurney AL. Interleukin-23 promotes a distinct $\mathrm{CD} 4 \mathrm{~T}$ cell activation state characterized by the production of interleukin-17. J Biol Chem. (2003) 278:1910-4. doi: 10.1074/jbc.M207577200

43. Veldhoen M, Hocking RJ, Atkins CJ, Locksley RM, Stockinger B. TGFbeta in the context of an inflammatory cytokine milieu supports de novo differentiation of IL-17-producing T cells. Immunity. (2006) 24:17989. doi: 10.1016/j.immuni.2006.01.001

44. Rachitskaya AV, Hansen AM, Horai R, Li Z, Villasmil R, Luger D, et al. Cutting edge: NKT cells constitutively express IL-23 receptor and RORgammat and rapidly produce IL-17 upon receptor ligation in an IL-6-independent fashion. J Immunol. (2008) 180:5167-71. doi: 10.4049/jimmunol.180.8.5167

45. Sutton CE, Lalor SJ, Sweeney CM, Brereton CF, Lavelle EC, Mills KH. Interleukin-1 and IL-23 induce innate IL-17 production from gammadelta $\mathrm{T}$ cells, amplifying Th17 responses and autoimmunity. Immunity. (2009) 31:331-41. doi: 10.1016/j.immuni.2009.08.001

46. Takatori H, Kanno Y, Watford WT, Tato CM, Weiss G, Ivanov, et al. Lymphoid tissue inducer-like cells are an innate source of IL-17 and IL-22. J Exp Med. (2009) 206:35-41. doi: 10.1084/jem.20072713

47. Murphy CA, Langrish CL, Chen Y, Blumenschein W, McClanahan T, Kastelein RA, et al. Divergent pro- and antiinflammatory roles for IL-23 and IL-12 in joint autoimmune inflammation. J Exp Med. (2003) 198:19517. doi: $10.1084 / \mathrm{jem} .20030896$

48. Cua DJ, Sherlock J, Chen Y, Murphy CA, Joyce B, Seymour B, et al. Interleukin-23 rather than interleukin-12 is the critical cytokine for autoimmune inflammation of the brain. Nature. (2003) 421:7448. doi: 10.1038/nature01355

49. Hue S, Ahern P, Buonocore S, Kullberg MC, Cua DJ, McKenzie BS, et al. Interleukin-23 drives innate and T cell-mediated intestinal inflammation. $J$ Exp Med. (2006) 203:2473-83. doi: 10.1084/jem.20061099

50. Benham H, Rehaume LM, Hasnain SZ, Velasco J, Baillet AC, Ruutu M, et al. Interleukin-23 mediates the intestinal response to microbial beta-1,3-glucan and the development of spondyloarthritis pathology in SKG mice. Arthritis Rheumatol. (2014) 66:1755-67. doi: 10.1002/art.38638

51. Duerr RH, Taylor KD, Brant SR, Rioux JD, Silverberg MS, Daly MJ, et al. A genome-wide association study identifies IL23R as an inflammatory bowel disease gene. Science. (2006) 314:1461-3. doi: 10.1126/science.1135245

52. De Vos M, Cuvelier C, Mielants H, Veys E, Barbier F, Elewaut A. Ileocolonoscopy in seronegative spondylarthropathy. Gastroenterology. (1989) 96(2 Pt 1):339-44. doi: 10.1016/0016-5085(89)91557-6

53. Sarin R, Wu X, Abraham C. Inflammatory disease protective R381Q IL23 receptor polymorphism results in decreased primary CD4+ and CD8+ human T-cell functional responses. Proc Natl Acad Sci USA. (2011) 108:95605. doi: 10.1073/pnas. 1017854108

54. Baeten D, Sieper J, Braun J, Baraliakos X, Dougados M, Emery P, et al. Secukinumab, an Interleukin-17A Inhibitor, in Ankylosing Spondylitis. N Engl J Med. (2015) 373:2534-48. doi: 10.1056/NEJMoa1505066

55. van der Heijde D, J. Cheng-Chung Wei, Dougados M, Mease P, Deodhar A, Maksymowych WP, et al. Ixekizumab, an interleukin-17A antagonist in the treatment of ankylosing spondylitis or radiographic axial spondyloarthritis in patients previously untreated with biological disease-modifying antirheumatic drugs (COAST-V):16 week results of a phase 3 randomised, double-blind, active-controlled and placebo-controlled trial. Lancet. (2018) 392:2441-51. doi: 10.1016/S0140-6736(18)31946-9

56. Baeten D, Ostergaard M, Wei JC, Sieper J, Jarvinen P, Tam LS, et al. Risankizumab, an IL-23 inhibitor, for ankylosing spondylitis: results of a randomised, double-blind, placebo-controlled, proofof-concept, dose-finding phase 2 study. Ann Rheum Dis. (2018) 77:1295-302. doi: 10.1136/annrheumdis-2018-213328

57. Deodhar A, Gensler LS, Sieper J, Clark M, Calderon C, Wang Y, et al. Three multicenter, randomized, double-blind, placebo-controlled studies evaluating the efficacy and safety of ustekinumab in axial spondyloarthritis. Arthritis Rheumatol. (2019) 71:258-70. doi: 10.1002/art.40728

58. Leonardi CL, Kimball AB, Papp KA, Yeilding N, Guzzo C, Wang Y, et al. Efficacy and safety of ustekinumab, a human interleukin-12/23 monoclonal antibody, in patients with psoriasis: 76-week results from a randomised, double-blind, placebo-controlled trial (PHOENIX 1). Lancet. (2008) 371:1665-74. doi: 10.1016/S0140-6736(08)60725-4

59. Al-Janabi A, Jabbar-Lopez ZK, C.Griffiths EM, Z.Yiu ZN. Risankizumab vs. ustekinumab for plaque psoriasis: a critical appraisal. Br J Dermatol. (2019) 180:1348-51. doi: 10.1111/bjd.17624

60. Feagan BG, Sandborn WJ, D'Haens G, Panes J, Kaser A, Ferrante $\mathrm{M}$, et al. Induction therapy with the selective interleukin-23 inhibitor risankizumab in patients with moderate-to-severe Crohn's disease: a randomised, double-blind, placebo-controlled phase 2 study. Lancet. (2017) 389:1699-709. doi: 10.1016/S0140-6736(17)30570-6

61. Feagan BG, Sandborn WJ, Gasink C, Jacobstein D, Lang Y, Friedman JR, et al. Ustekinumab as induction and maintenance therapy for Crohn's disease. $N$ Engl J Med. (2016) 375:1946-60. doi: 10.1056/NEJMoa1602773

62. Hueber W, Sands BE, Lewitzky S, Vandemeulebroecke M, Reinisch W, Higgins PD, et al. Secukinumab, a human anti-IL-17A monoclonal antibody, for moderate to severe Crohn's disease: unexpected results of a randomised, double-blind placebo-controlled trial. Gut. (2012) 61:1693700. doi: 10.1136/gutjnl-2011-301668

63. Acosta-Rodriguez EV, Napolitani G, Lanzavecchia A, Sallusto F. Interleukins lbeta and 6 but not transforming growth factor-beta are essential for the differentiation of interleukin 17-producing human T helper cells. Nat Immunol. (2007) 8:942-9. doi: 10.1038/ni1496 
64. Zielinski CE, Mele F, Aschenbrenner D, Jarrossay D, Ronchi F, Gattorno M, et al. Pathogen-induced human TH17 cells produce IFN-gamma or IL-10 and are regulated by IL-1beta. Nature. (2012) 484:514-8. doi: 10.1038/nature10957

65. Doisne JM, Soulard V, Becourt C, Amniai L, Henrot P, Havenar-Daughton C, et al. Cutting edge: crucial role of IL-1 and IL-23 in the innate IL-17 response of peripheral lymph node NK1.1 - invariant NKT cells to bacteria. J Immunol. (2011) 186:662-6. doi: 10.4049/jimmunol.1002725

66. McGinley AM, Sutton CE, Edwards SC, Leane CM, DeCourcey J, Teijeiro A, et al. Interleukin-17A serves a priming role in autoimmunity by recruiting IL-1beta-producing myeloid cells that promote pathogenic T cells. Immunity. (2020) 52:342-56 e6. doi: 10.1016/j.immuni.2020.01.002

67. Conrad K, Wu P, Sieper J, Syrbe U. 31848486 In vivo pre-activation of monocytes in patients with axial spondyloarthritis. Arthritis Res Ther. (2015). 17:179. doi: 10.1186/s13075-015-0694-2

68. Jain A, Irizarry-Caro RA, McDaniel MM, Chawla AS, Carroll KR, Overcast $\mathrm{GR}$, et al. T cells instruct myeloid cells to produce inflammasomeindependent IL-1beta and cause autoimmunity. Nat Immunol. (2020) 21:6574. doi: 10.1038/s41590-019-0559-y

69. Tan AL, Marzo-Ortega H, O'Connor P, Fraser A, Emery P, McGonagle D. Efficacy of anakinra in active ankylosing spondylitis: a clinical and magnetic resonance imaging study. Ann Rheum Dis. (2004) 63:10415. doi: 10.1136/ard.2004.020800

70. Haibel H, Rudwaleit M, Listing J, Sieper J. Open label trial of anakinra in active ankylosing spondylitis over 24 weeks.
Ann Rheum Dis. (2005) 64:296-8. doi: 10.1136/ard.2004.0 23176

71. Bennett AN, Tan AL, Coates LC, Emery P, Marzo-Ortega H, McGonagle D. Sustained response to anakinra in ankylosing spondylitis. Rheumatology (Oxford). (2008) 47:223-4. doi: 10.1093/rheumatology/kem302

72. Fang H, U.-Consortium D, De Wolf H, Knezevic B, Burnham KL, Osgood J, et al. A genetics-led approach defines the drug target landscape of 30 immune-related traits. Nat Genet. (2019) 51:108291. doi: 10.1038/s41588-019-0456-1

73. Siebert S, Millar NL, McInnes IB. Why did IL-23p19 inhibition fail in AS: a tale of tissues, trials or translation? Ann Rheum Dis. (2019) 78:10158. doi: 10.1136/annrheumdis-2018-213654

Conflict of Interest: The authors declare that the research was conducted in the absence of any commercial or financial relationships that could be construed as a potential conflict of interest.

Copyright (c) 2021 Nancy, Yan, Hui, Paul and Liye. This is an open-access article distributed under the terms of the Creative Commons Attribution License (CC BY). The use, distribution or reproduction in other forums is permitted, provided the original author(s) and the copyright owner(s) are credited and that the original publication in this journal is cited, in accordance with accepted academic practice. No use, distribution or reproduction is permitted which does not comply with these terms. 